ARTIGO ORIGINAL

\title{
Características termogravimétricas e combustão da madeira de Tachigali vulgaris proveniente de plantios com diferentes espaçamentos
}

\author{
Thermogravimetric characteristics and combustion of Tachigali vulgaris wood \\ planted at different spacings
}

\author{
Marilene Olga dos Santos Silva ${ }^{1}$, , Marcela Gomes da Silva ${ }^{1}$ (D), Lina Bufalino ${ }^{1}$ (i), Maíra Reis de Assis $^{2}$ (D), \\ Delman de Almeida Gonçalves ${ }^{3}$ (1) , Paulo Fernando Trugilho $^{2}$ (1) , Thiago de Paula Protásio ${ }^{4}$ (i) \\ ${ }^{1}$ Universidade Federal Rural da Amazônia - UFRA, Belém, PA, Brasil \\ ¿Universidade Federal de Lavras - UFLA, Lavras, MG, Brasil \\ ${ }^{3}$ Empresa Brasileira de Pesquisa Agropecuária - EMBRAPA Amazônia Oriental, Belém, PA, Brasil \\ ${ }^{4}$ Universidade Federal Rural da Amazônia - UFRA, Parauapebas, PA, Brasil
}

\begin{abstract}
Como citar: Silva, M. O. S., Silva, M. G., Bufalino, L., Assis, M. R., Gonçalves, D. A., Trugilho, P. F., \& Protásio, T. P. (2021). Características termogravimétricas e combustão da madeira de Tachigali vulgaris proveniente de plantios com diferentes espaçamentos. Scientia Forestalis, 49(129), e3164. https://doi.org/10.18671/scifor.v49n129.01
\end{abstract}

\begin{abstract}
Resumo
O Tachigali vulgaris (tachi-branco) é uma espécie madeireira da Amazônia, comumente utilizada para finalidades energéticas por populações locais. O conhecimento da cinética de degradação térmica da sua madeira é essencial para adequar os processos de conversão termoquímica visando à produção direta de energia ou de carvão vegetal. Portanto, o objetivo deste estudo foi avaliar o comportamento térmico da madeira do tachi-branco proveniente de diferentes espaçamentos de plantio, durante a combustão e pirólise. Foram coletadas árvores da espécie aos 87 meses de idade de um plantio experimental, localizado no Distrito de Monte Dourado, Pará, Brasil, cultivadas em diferentes espaçamentos de 3,0 x 1,5 m, 3,0 × 2,0 m, 3,0 × 2,5 m, 3,0 × 3,0 m, 3,0 × 3,5 m e 3,0 × 4,0 m. Para a pirólise da madeira, as curvas TG (termogravimétrica) e DTG (primeira derivada da termogravimétrica), sob atmosfera inerte de nitrogênio, exibiram três estágios distintos de perda de massa, correspondentes à degradação térmica das hemiceluloses, celulose e lignina. A faixa de temperatura para a decomposição das hemiceluloses variou de $280^{\circ} \mathrm{C}$ a $320^{\circ} \mathrm{C}$, com perda de massa de $17 \%$. Para a celulose a faixa foi de $340^{\circ} \mathrm{C}$ a $380^{\circ} \mathrm{C}$ com perda de massa de aproximadamente $50 \%$. A partir de temperaturas próximas a $400^{\circ} \mathrm{C}$, a degradação térmica da madeira diminuiu, correspondendo principalmente à degradação de lignina, com perda de massa de 5\%. Madeiras provenientes dos espaçamentos 3,0 x 2,0 m, 3,0 x 2,5 m e 3,0 x 3,0 m foram as que apresentaram maior massa residual, o que sugere maior rendimento em carvão vegetal. Para a combustão, observaram-se duas reações principais de decomposição, correspondendo à volatilização das hemiceluloses, celulose e parte da lignina. No segundo estágio, ocorreu a decomposição da lignina remanescente e do carbono fixo. Independente do espaçamento de plantio, a baixa temperatura de ignição $\left(233,7^{\circ} \mathrm{C}\right)$, aliada à elevada temperatura final da combustão $\left(451,6^{\circ} \mathrm{C}\right)$ e ao elevado índice de ignição $\left(4 \times 10^{3} \% / \mathrm{min}^{3}\right)$, demonstram que a espécie apresenta características adequadas para a produção direta de energia térmica.
\end{abstract}

Palavras-chave: Tachi-branco; Combustão; Pirólise; Termogravimetria.

\section{Abstract}

Tachigali vulgaris (tachi-branco) is a woody species of Amazonia commonly used for energetic purposes by local populations. The knowledge of kinetics of the thermal degradation of its wood is essential to adequate the thermos-chemical conversion processes aiming at the direct production of energy or

Fonte de financiamento: CNPq (código de financiamento 306793/2019-9), CAPES (código de financiamento 001), EMBRAPA Amazônia Oriental e Jari Celulose. Conflito de interesse: Nada a declarar.

Autor correspondente: marileneengenhariaf@gmail.com

Recebido: 14 outubro 2018.

Aceito: 3 abril 2020.

Editor: Paulo Henrique Müller Silva.

(c) (i) Este é um artigo publicado em acesso aberto (Open Access) sob a licença Creative Commons Attribution, que permite uso, distribuição e reprodução em qualquer meio, sem restrições desde que o trabalho original seja corretamente citado. 
charcoal. Therefore, the aim of this study is to evaluate the thermal behavior of tachi-branco wood from different crop spacings during combustion and pyrolysis. 7-years old trees were harvested from an experimental trial, located at Monte Dourado, Pará, Brasil, planted at different spacings of $3.0 \times 1.5 \mathrm{~m}$, $3.0 \times 2.0 \mathrm{~m}, 3.0 \times 2.5 \mathrm{~m}, 3.0 \times 3.0 \mathrm{~m}, 3.0 \times 3.5 \mathrm{~m}$ and $3.0 \times 4.0 \mathrm{~m}$. For wood pyrolysis under inert nitrogen atmosphere, the TG (thermos-gravimetric) and DTG (first derivative of the thermos-gravimetric) curves exhibited three different stages of mass loss that correspond to thermal degradation of hemicelluloses, cellulose and lignin. The temperature range for hemicelluloses decomposition varied from $280^{\circ} \mathrm{C}$ to $320^{\circ} \mathrm{C}$, with mass loss of $17 \%$. For cellulose, the range was from $340^{\circ} \mathrm{C}$ to $380^{\circ} \mathrm{C}$ with mass loss of about $50 \%$. From the temperatures near $400^{\circ} \mathrm{C}$ on, the wood thermal degradation decreased, with mass loss of $5 \%$. The wood from $3.0 \times 2.0 \mathrm{~m}, 3.0 \times 2.5 \mathrm{~m}$ and $3.0 \times 3.0 \mathrm{~m}$ spacings showed higher residual mass, which suggests higher charcoal yield. For the combustion, two main decomposition reactions were observed, corresponding to the volatilization of hemi-celluloses, cellulose, and a fraction of lignin. At the second stage, the decomposition of the remaining lignin and fixed carbon occurred. Regardless of the tree spacing, the low ignition temperature $\left(233.7^{\circ} \mathrm{C}\right)$, the high final combustion temperature $\left(451.6^{\circ} \mathrm{C}\right)$ and the high ignition $\left(4 \times 10^{3} \% / \mathrm{min}^{3}\right)$ index showed that the species show adequate characteristics for the direct production of thermal energy.

Keywords: Tachi-branco; Combustion; Pyrolysis; Thermo-gravimetrics.

\section{INTRODUÇÃO}

A obtenção de energia da madeira a partir do fornecimento de altas temperaturas promove a decomposição térmica dos seus componentes químicos, processo denominado pirólise ou carbonização, quando ocorre sob atmosfera inerte, e combustão quando ocorre sob atmosfera oxidante (Carneiro et al., 2013). O processo de pirólise pode ser considerado como a sobreposição da decomposição térmica dos seus três componentes majoritários, além da perda de água do material (Pereira et al., 2013). Já a combustão é a oxidação completa de um combustível que ocorre a uma faixa de temperatura de $250^{\circ} \mathrm{C}$ a $800^{\circ} \mathrm{C}$, na qual o carbono e o hidrogênio da madeira se combinam com o oxigênio para formar $\mathrm{CO}_{2}$ e $\mathrm{H}_{2} \mathrm{O}$, liberando energia quando o combustível atinge a temperatura de ignição (García et al., 2012).

Por meio da análise termogravimétrica (TGA), é possível investigar e comparar os eventos térmicos durante a combustão e pirólise de pequenas amostras de combustível e medir as variações de massa durante o aquecimento. Essas técnicas são amplamente aplicadas para o estudo da decomposição da madeira e seus principais componentes, a celulose, as hemiceluloses e a lignina (García et al., 2012; Protásio et al., 2019). Entretanto, a decomposição térmica da biomassa é fortemente influenciada pelas suas características físicas e químicas e estas, por sua vez, variam de acordo com as espécies, localização dentro da árvore, condições de crescimento e de manejo (Ragland et al., 1991).

Para a madeira de eucalipto, por exemplo, a curva TGA sugere que a combustão da madeira ocorre em duas etapas principais, em que a primeira fase varia de 200 a $360^{\circ} \mathrm{C}$ devido à degradação térmica das hemiceluloses, celulose e parte da lignina. Já a segunda fase ocorre aproximadamente entre 360 e $460^{\circ} \mathrm{C}$ devido à decomposição da lignina restante e do carbono fixo formado durante a primeira etapa. A composição química da espécie, especialmente a quantidade de unidades guaiacil da lignina e os extrativos solúveis em acetona influenciam o desempenho da combustão e resultam em alta estabilidade térmica e tempo de combustão (Protásio et al., 2019). Além da espécie, as variações físico-químicas das madeiras provenientes de árvores com diferentes tratos silviculturais podem influenciar a eficiência dos processos termoquímicos de conversão e a qualidade dos combustíveis de biomassa (Rocha et al., 2016).

Os diferentes espaçamentos em que a árvore é submetida alteram as condições de crescimento e formação de xilema secundário. Essa modificação pode ocasionar variações nos componentes celulares da madeira e, consequentemente, alterações nas propriedades energéticas do material (Moulin et al., 2015). Para espécies do gênero Eucalyptus, o efeito do espaçamento de plantio nas características de crescimento e da madeira é amplamente relatado na literatura (Eloy et al., 2015; Rocha et al., 2016; Eufrade-Junior et al., 2018). Rocha et al. (2016) reportaram que o espaçamento de plantio influenciou significativamente a densidade básica e composição química da madeira de Eucalyptus. Os autores constataram 
que as árvores plantadas com espaçamentos de 4,5 a 9,0 $\mathrm{m}^{2}$ apresentaram densidade da madeira aproximadamente $8 \%$ maior que os seus clones plantados em espaçamento reduzido $\left(1,5 \mathrm{~m}^{2}\right)$. Adicionalmente, foi verificado que o teor de lignina das madeiras proveniente dos espaçamentos 6,0 e $9,0 \mathrm{~m}^{2}$ foi aproximadamente $12 \%$ superior ao da madeira do espaçamento de $3,0 \mathrm{~m}^{2}$. O acréscimo do teor de lignina pode aumentar o teor de carbono fixo e, consequentemente, a estabilidade térmica e a duração da combustão da madeira (Protásio et al., 2019). A relação entre os constituintes químicos da madeira, como a maior proporção de materiais voláteis em relação ao teor de carbono, pode aumentar a intensidade da combustão e o consumo de massa (Lewandowski \& Kicherer, 1997; Protásio et al., 2019). Dessa forma, é necessário compreender o desempenho da madeira submetida a distintas condições de crescimento, especialmente para espécies alternativas de interesse bioenergético em plantios experimentais.

A espécie Tachigali vulgaris L. G. Silva \& H.C. Lima é uma leguminosa arbórea, nativa da região Amazônica, que durante muito tempo tem sido recomendada para carvoaria. Além do tachi-branco ser o mais conhecido, o seu potencial energético originou o seu nome popular, carvoeiro (Rolim \& Piotto, 2018). A possibilidade de uso do T. vulgaris na recuperação de áreas degradadas e o potencial silvicultural e energético da espécie já foram confirmados em pesquisas dos últimos 36 anos, em que foram observados valores de densidade básica de $0,493 \mathrm{~g} / \mathrm{cm}^{3}$ a $0,633 \mathrm{~g} / \mathrm{cm}^{3}$, poder calorífico superior de $4390 \mathrm{kcal} / \mathrm{kg}$ a $4567 \mathrm{kcal} / \mathrm{kg}$ (Tomaselli et al., 1983; Farias et al., 2016; Orellana et al., 2018; Silva et al., 2021) e incremento médio anual superior a $40 \mathrm{~m}^{3} / \mathrm{ha}$.ano (Souza et al., 2008). Farias et al. (2016) relataram que, na recuperação de áreas degradadas, o T. vulgaris teve melhor desempenho em todos os índices, comparativamente ao Eucalyptus urophylla x Eucalyptus grandis, mostrando 52\% de sobrevivência e produzindo $241,7 \mathrm{Mg} / \mathrm{ha}$ de biomassa, após quatro anos.

O rápido crescimento da espécie $T$. vulgaris em plantios homogêneos foi observado por Souza et al. (2008). Os pesquisadores avaliaram o desempenho de espécies florestais para usos múltiplos na Amazônia e observaram que o T. vulgaris apresentou destaque quanto à produtividade volumétrica, comparativamente a Acacia mangium, Carapa guianensis, Trattinickia burseraefolia, Bertholettia excelsa, Cedrela odorata, Copaifera multijuga, Dipteryx odorata, Hymenaea courbaril e Swietenia macrophylla. No espaçamento $3 \times 3 \mathrm{~m}$, o tachi-branco apresentou produção de $475,6 \mathrm{~m}^{3} /$ ha e incremento médio anual em volume de $43,2 \mathrm{~m}^{3}$ ha/ano, aos 11 anos de idade (Souza et al., 2008). As pesquisas recentes publicadas na literatura se concentram em estudar a produtividade energética dos plantios (Orellana et al., 2018) e a qualidade da madeira de T. vulgaris sob diferentes espaçamentos (Tonini et al., 2018; Silva et al., 2021). Entretanto, até o momento, não foi avaliado o comportamento térmico da madeira de $T$. vulgaris proveniente de plantios homogêneos com diferentes espaçamentos, essencial para seu correto aproveitamento para finalidades energéticas.

Portanto, o objetivo do presente estudo foi avaliar o comportamento térmico da madeira do carvoeiro proveniente de diferentes espaçamentos, durante a combustão e pirólise.

\section{MATERIAL E MÉTODOS}

\section{Caracterização da área de estudo}

$O$ experimento foi realizado em um plantio experimental de aproximadamente 6 hectares, pertencente à empresa Jari Celulose S.A., localizado no distrito de Monte Dourado, Pará, Brasil, situado entre as coordenadas geográficas $0^{\circ} 55^{\prime} 33^{\prime \prime} \mathrm{S}$ e $52^{\circ} 25^{\prime} 51^{\prime \prime} \mathrm{O}$. Na área a temperatura média anual é de aproximadamente $26^{\circ} \mathrm{C}$ (Demolinari et al., 2007).

O solo da região é classificado como Latossolo Amarelo distrófico, textura média. Foi realizada uma aplicação de calcário (402 kg/ha) no plantio. Além disso, foram aplicados $150 \mathrm{~kg} / \mathrm{ha}$ de NPK 6-30-6 e 85 kg/ha de NPK 15-0-30 no primeiro e segundo anos de plantio, respectivamente.

A área de plantio foi subdividida em três blocos para buscar minimizar possíveis variações de fertilidade ao longo do terreno. Foram selecionadas de forma aleatória 31 
árvores de fuste único e 23 árvores bifurcadas (pelo menos duas por espaçamento), excluindo-se aquelas que apresentavam defeitos visíveis e as que estavam localizadas nas bordas dos plantios. As árvores bifurcadas correspondem a 51,6\% do plantio da espécie, portanto optou-se por amostrá-las em função da representatividade. Neste estudo, foram avaliados seis espaçamentos ( $3 \times 1,5 \mathrm{~m}, 3 \times 2,0 \mathrm{~m}, 3 \times 2,5 \mathrm{~m}, 3 \times 3,0 \mathrm{~m}, 3 \times 3,5 \mathrm{~m}$ e $3 \times 4,0 \mathrm{~m}) \mathrm{e}$ 54 árvores (3 árvores $\times 3$ blocos $\times 6$ espaçamentos) da espécie T. vulgaris, aos 87 meses de idade.

\section{Coleta e preparo do material}

Para as árvores de fuste único, seis discos foram obtidos na base (0\%), DAP, 25\%, 50\%, $75 \%$ e $100 \%$ da altura comercial da árvore, até o diâmetro mínimo de $5 \mathrm{~cm}$ com casca. Para as árvores bifurcadas foram amostrados os fustes principal e secundário, levando em consideração a mesma metodologia.

Para a realização das análises termogravimétricas, uma cunha proveniente de cada posição de amostragem foi transformada em cavacos e, posteriormente, moída em um moinho do tipo willey. Foram utilizadas amostras compostas por todas as posições longitudinais de amostragem das três árvores coletadas em cada espaçamento e bloco. Dessa forma, foi ensaiada uma amostra representativa de cada espaçamento e bloco, totalizando três análises térmicas para cada tratamento e um total de dezoito análises termogravimétricas para cada processo termoquímico pesquisado (combustão e pirólise). As amostras utilizadas nos ensaios termogravimétricos passaram pela peneira de 60 mesh.

\section{Combustão da madeira de Tachigali vulgaris}

As análises termogravimétricas (TGA) e térmica diferencial (DTA) foram realizadas com o equipamento TGA-60 da marca SHIMADZU em atmosfera de oxigênio (combustão), a uma vazão constante de $50 \mathrm{ml} / \mathrm{min}$, sendo utilizados, aproximadamente, $4 \mathrm{mg}$ de amostra. As amostras foram submetidas ao ensaio a partir da temperatura ambiente até a temperatura máxima de $600^{\circ} \mathrm{C}$, a uma taxa de aquecimento de $5^{\circ} \mathrm{C} / \mathrm{min}$ em atmosfera de oxigênio.

Com base nas curvas de TG e DTG, em atmosfera oxidante, foram obtidos os seguintes parâmetros de combustão: temperatura de ignição (Ti); temperatura final da combustão (Tf); índice característico da combustão (S); índice de ignição (Di); tempo correspondente à máxima taxa de combustão (tp); tempo de ignição (tig); taxa máxima de combustão; taxa média de combustão e, temperaturas máximas em cada estágio da combustão.

A temperatura de ignição da madeira foi definida como a temperatura na qual a taxa de combustão aumentou a $1 \% / \mathrm{min}$, ou seja, quando se iniciou o maior processo de combustão. A temperatura final do processo de combustão foi definida como a temperatura na qual a taxa de combustão diminuiu a 1\%/min (Moon et al., 2013; Sahu et al., 2010; Protásio et al., 2017). Para determinar o índice de combustão (S), foi utilizada a equação proposta por Moon et al. (2013):

$$
S=\frac{\left(\frac{d w}{d t}\right) \text { máx }\left(\frac{d w}{d t}\right) \text { média }}{T_{i}^{2} T_{f}}
$$

Em que:

$\left(\frac{d w}{d t}\right)$ máx é a máxima taxa de perda de massa em $\% /$ min

$\left(\frac{d w}{d t}\right)$ média é a média taxa de perda de massa em $\% / \mathrm{min}$

$T_{i}$ é a temperatura de ignição em ${ }^{\circ} \mathrm{C}$

$T_{f}$ é a temperatura final da combustão em ${ }^{\circ} \mathrm{C}$ 
Para a determinação do índice de ignição (Di), foi utilizada a equação proposta por Qian et al. (2012):

$D i=\frac{\left(\frac{d w}{d t}\right) m a ́ x}{t_{p} t_{i g}}$

Em que:

$\left(\frac{d w}{d t}\right)$ máx é a taxa máxima de combustão em $\% / m i n$

$t_{p}$ é o tempo correspondente à máxima taxa de combustão (min)

$t_{i g}$ é o tempo de ignição (min)

\section{Pirólise da madeira de Tachigali vulgaris}

Para o ensaio de pirólise, as análises termogravimétricas foram realizadas com o equipamento TGA-60 da marca SHIMADZU em atmosfera de nitrogênio, a uma vazão constante de $30 \mathrm{ml} / \mathrm{min}$, sendo utilizados, aproximadamente, $4 \mathrm{mg}$ de amostra. As amostras foram submetidas ao ensaio a partir da temperatura ambiente até a temperatura máxima de $600^{\circ} \mathrm{C}$, a uma taxa de aquecimento de $10^{\circ} \mathrm{C} / \mathrm{min}$, em atmosfera de nitrogênio.

Para as análises de TGA em atmosfera de nitrogênio, calcularam-se, com base na massa inicial de cada amostra, as perdas de massa expressas em porcentagem, nos seguintes intervalos de temperatura: $30-100^{\circ} \mathrm{C} ; 100-200^{\circ} \mathrm{C} ; 200-300^{\circ} \mathrm{C} ; 300-400^{\circ} \mathrm{C} ; 400-500^{\circ} \mathrm{C}$; e 500 $600^{\circ} \mathrm{C}$. Os valores da massa residual foram obtidos a partir do somatório dos valores das perdas de massa observados em cada intervalo, decrescido de 100\%, conforme realizado por Santos et al. (2012).

\section{Análises estatísticas}

O experimento foi conduzido sob o delineamento em blocos ao acaso com seis espaçamentos iniciais de plantio e três blocos. Foram utilizadas três repetições para cada tratamento, ou seja, uma amostra por bloco experimental. De forma preliminar, os dados foram submetidos aos testes de Shapiro-Wilk para testar a normalidade, de Levene e Bartlett para testar a homogeneidade das variâncias e de Durbin-Watson para a autocorrelação de resíduos. Não foram observados desvios em relação aos pressupostos da análise de variância. Em seguida, procederam-se as análises de variância visando testar o efeito de espaçamento inicial de plantio nas características térmicas da madeira de T. vulgaris.

\section{RESULTADOS E DISCUSSÕES}

\section{Efeito do espaçamento na combustão da madeira de Tachigali vulgaris}

Não foi observado efeito significativo do espaçamento de plantio nos parâmetros da combustão da madeira de Tachigali vulgaris (Tabelas 1, 2 e 3).

O comportamento da madeira proveniente dos diferentes espaçamentos durante a degradação térmica foi semelhante, com perdas de massa mais acentuadas em faixas próximas de temperatura e com picos de energia liberada semelhantes, expressos pelas análises térmicas diferenciais. Provavelmente, isso ocorreu devido à baixa variação da composição química imediata da madeira do tachi-branco nos diferentes espaçamentos analisados, uma vez que os teores de materiais voláteis e carbono fixo afetam diretamente o comportamento dos materiais lignocelulósicos durante a combustão (Protásio et al., 2017, 2019). Silva et al. (2021) observaram teores de materiais voláteis da madeira do tachi-branco de $78,27 \%, 78,48 \%, 78,64 \%, 78,86 \%, 78,30 \%$ e $78,69 \%$ para os espaçamentos de $3 \times 1,5 \mathrm{~m}, 3 \times$ $2,0 \mathrm{~m}, 3 \times 2,5 \mathrm{~m}, 3 \times 3,0 \mathrm{~m}, 3 \times 3,5 \mathrm{~m}$ e $3 \times 4,0 \mathrm{~m}$, respectivamente. Adicionalmente, vale 
salientar que os autores constataram que o espaçamento de plantio não influenciou o teor de carbono fixo da madeira de $T$. vulgaris.

Tabela 1. Análise de variância para a perda de massa e temperatura máxima para cada estágio de decomposição da madeira, sob atmosfera oxidativa.

\begin{tabular}{cccccc}
\hline \multirow{2}{*}{ FV } & GL & \multicolumn{4}{c}{ Quadrado médio } \\
\cline { 3 - 6 } & & \multicolumn{2}{c}{$\mathbf{1}^{\mathbf{0}}$ Estágio } & \multicolumn{2}{c}{$\mathbf{2}^{\circ}$ Estágio } \\
\hline & & $\mathbf{P M}$ & $\mathbf{T M}$ & $\mathbf{P M}$ & $\mathbf{T M}$ \\
Espaçamento & 5 & $3,1646^{\mathrm{ns}}$ & $1,4966^{\mathrm{ns}}$ & $2,245^{\mathrm{ns}}$ & $16,281^{\mathrm{ns}}$ \\
Bloco & 2 & $1,0239^{\text {ns }}$ & $0,6439^{\mathrm{ns}}$ & $0,855^{\mathrm{ns}}$ & $14,562^{\mathrm{ns}}$ \\
Erro & 10 & 1,4306 & 0,8126 & 0,741 & 6,194 \\
Média Geral & - & 73,5 & 300,0 & 21,6 & 441,2 \\
Cve (\%) & - & 1,63 & 0,30 & 3,98 & 0,57 \\
\hline
\end{tabular}

$\mathrm{FV}$ = fonte de variação; $\mathrm{GL}$ = graus de liberdade; $\mathrm{PM}=$ perda de massa; $\mathrm{TM}$ = temperatura máxima; ns = não significativo a $5 \%$ de probabilidade, pelo teste $\mathrm{F}$; $\mathrm{CVe}=$ coeficiente de variação experimental.

Tabela 2. Análise de variância para os parâmetros da combustão.

\begin{tabular}{|c|c|c|c|c|c|}
\hline \multirow{2}{*}{ FV } & \multirow{2}{*}{ GL } & \multicolumn{4}{|c|}{ Quadrado médio } \\
\hline & & $\mathrm{Ti}$ & Tf & $(d m / d t)_{\text {máx }}$ & $(\mathrm{dm} / \mathrm{dt})_{\text {médio }}$ \\
\hline Espaçamento & 5 & $2,5969^{\text {ns }}$ & $9,0357^{\mathrm{ns}}$ & $0,050179^{n s}$ & $0,00084889^{\text {ns }}$ \\
\hline Bloco & 2 & $1,8822^{\text {ns }}$ & $7,2717^{\mathrm{ns}}$ & $0,092872^{\text {ns }}$ & $0,00202222^{\text {ns }}$ \\
\hline Erro & 10 & 2,8389 & 8,5843 & 0,094546 & 0,00266889 \\
\hline Média Geral & - & 233,7 & 451,6 & 8,96 & 1,11 \\
\hline CVe (\%) & - & 0,72 & 0,65 & 3,43 & 4,66 \\
\hline
\end{tabular}

$\mathrm{FV}=$ fonte de variação; $\mathrm{GL}$ = graus de liberdade; $\mathrm{Ti}$ = temperatura de ignição; $\mathrm{Tf}$ = temperatura final da combustão (burnout temperature); $(\mathrm{dm} / \mathrm{dt})$ máx = taxa de máxima perda de massa; $(\mathrm{dm} / \mathrm{dt}$ )médio = taxa média de perda de massa; ns = não significativo a $5 \%$ de probabilidade, pelo teste $\mathrm{F} ; \mathrm{CVe}=$ coeficiente de variação experimental.

Tabela 3. Análise de variância para os parâmetros da combustão (cont.).

\begin{tabular}{cccccc}
\hline \multirow{2}{*}{ FV } & GL & \multicolumn{4}{c}{ Quadrado médio } \\
\cline { 3 - 6 } & & tp & tig & $\mathbf{S}$ & Di \\
\hline Espaçamento & 5 & $0,91600^{\text {ns }}$ & $1,29256^{\text {ns }}$ & $0,011246^{\text {ns }}$ & $0,044382^{\text {ns }}$ \\
Bloco & 2 & $0,76167^{\text {ns }}$ & $0,97389^{\text {ns }}$ & $0,099939^{\text {ns }}$ & $0,026756^{\text {ns }}$ \\
Erro & 10 & 1,00367 & 1,28856 & 0,088919 & 0,067842 \\
Média Geral & & 54,1 & 40,9 & 4,03 & 4,05 \\
CVe (\%) & & 1,85 & 2,77 & 7,40 & 6,42 \\
\hline
\end{tabular}

$\mathrm{FV}$ = fonte de variação; $\mathrm{GL}$ = graus de liberdade; $\mathrm{tp}$ = tempo correspondente à máxima taxa de combustão; tig = tempo de ignição; $\mathrm{S}=$ índice de combustão; $\mathrm{Di}$ = índice de ignição; ns = não significativo 5\% de probabilidade, pelo teste $\mathrm{F}$; $\mathrm{CVe}=$ coeficiente de variação experimental.

A combustão da madeira do tachi-branco pode ser dividida em duas reações principais (Figuras 1, 2 e 3). A primeira é a volatilização dos principais constituintes da biomassa e produção de carbono fixo. Posteriormente, na segunda fase, ocorre a combustão desse carbono sólido gerado nos estágios iniciais (García et al., 2012; Li et al., 2013; LópezGonzález et al., 2013). 


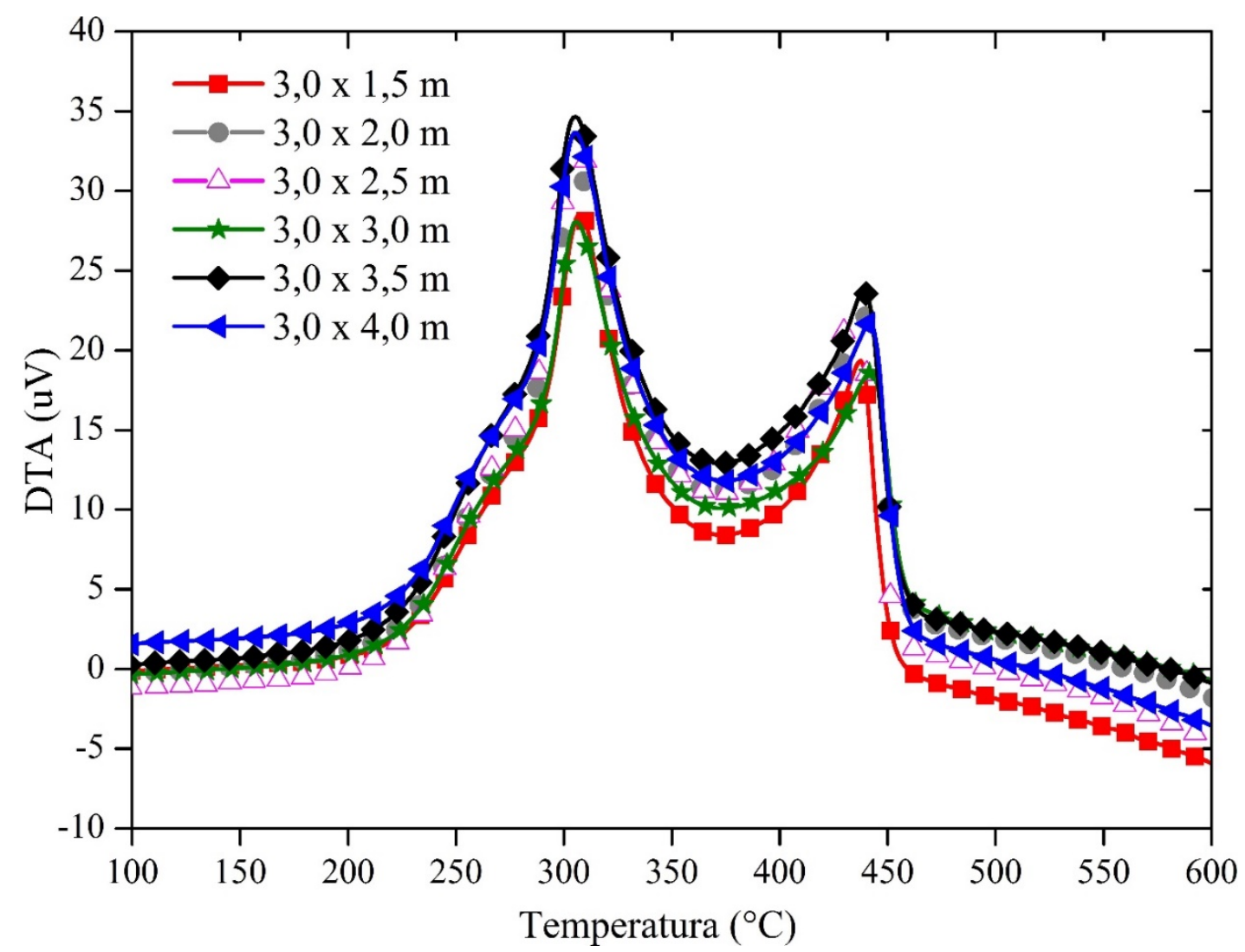

Figura 1. Análise térmica diferencial (DTA) da combustão da madeira de tachi-branco.

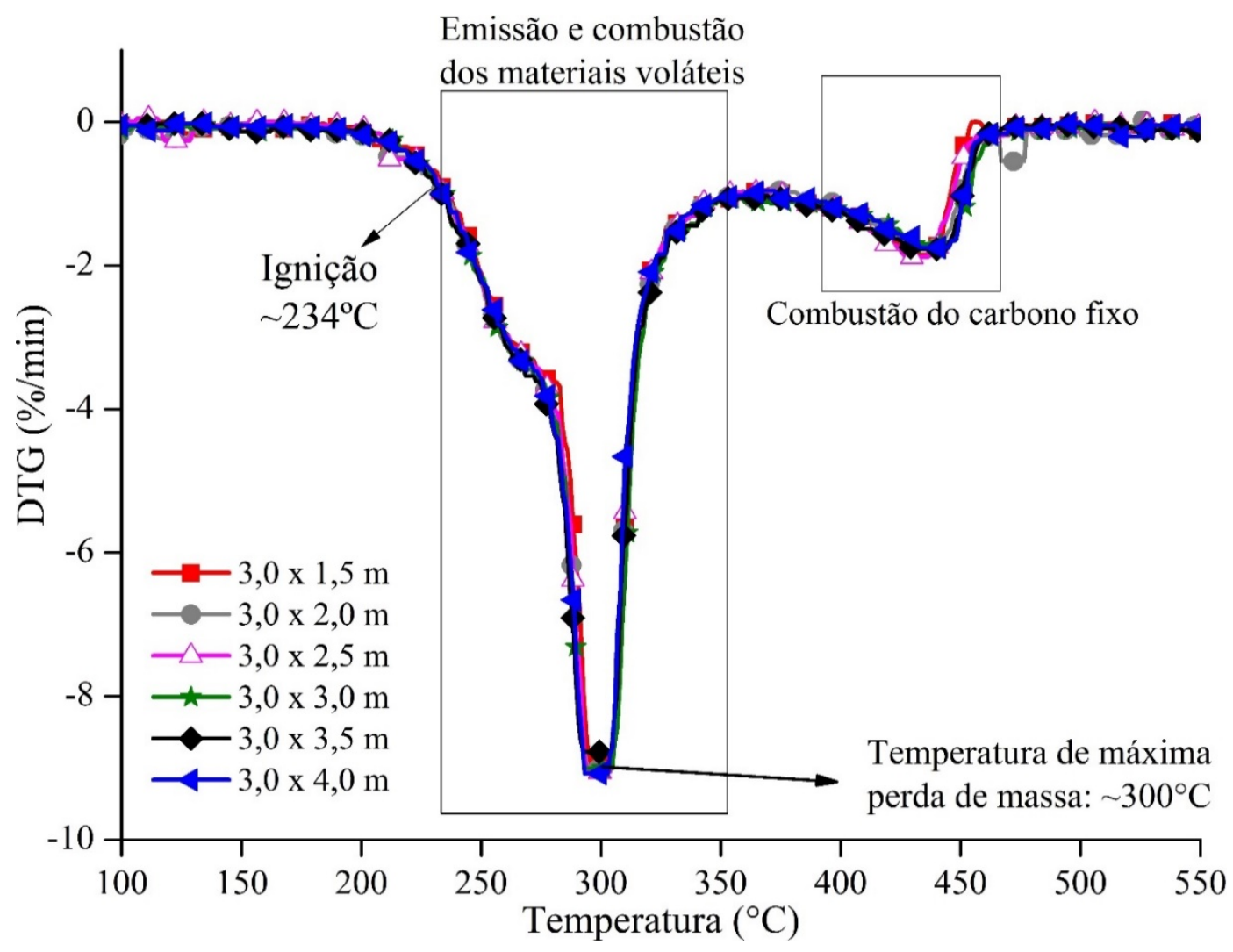

Figura 2. Curvas DTG da madeira de tachi-branco durante a combustão. 


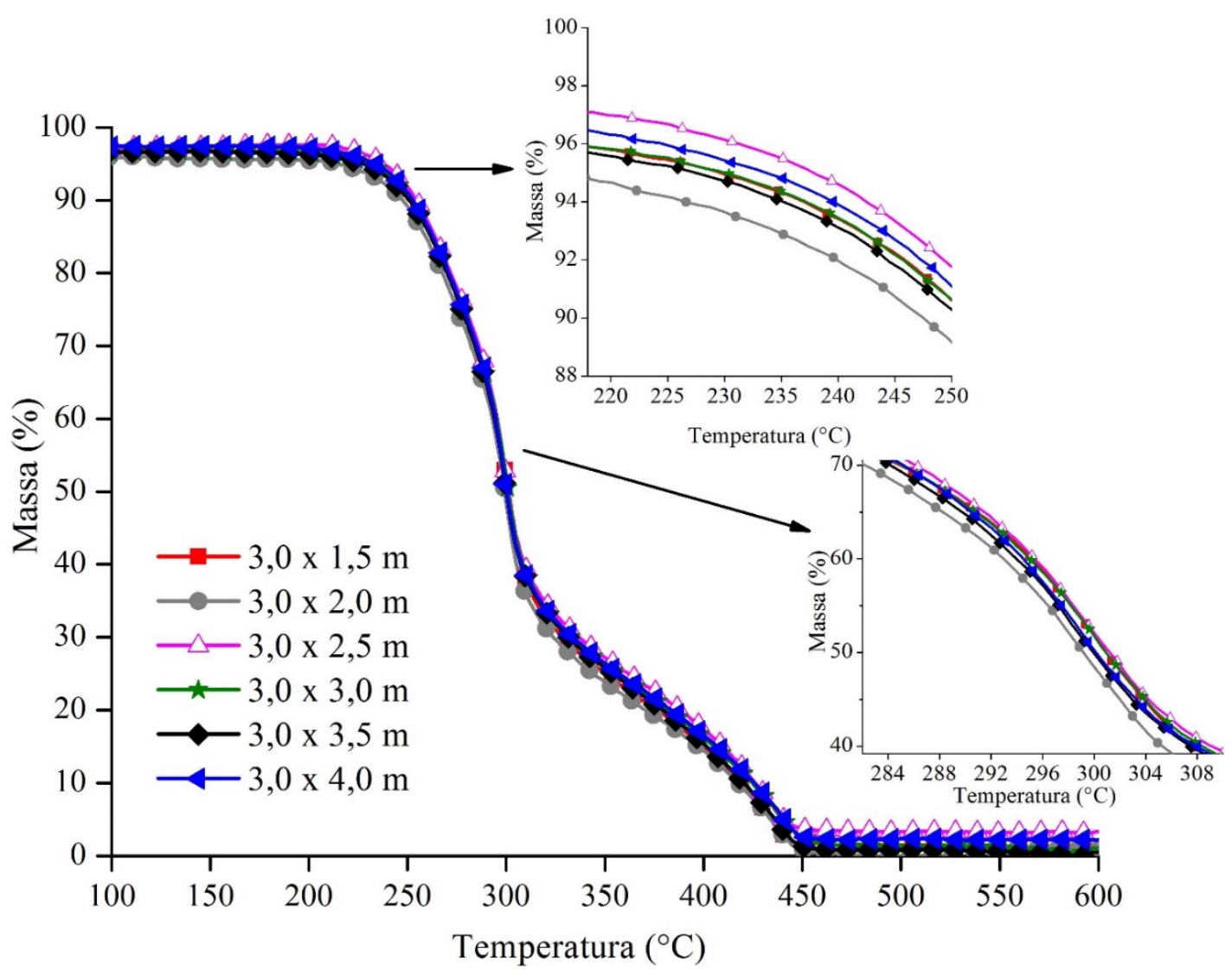

Figura 3. Curvas termogravimétricas da madeira de tachi-branco durante a combustão.

O primeiro estágio da combustão está compreendido entre as temperaturas de $250^{\circ} \mathrm{C}$ e $350^{\circ} \mathrm{C}$, com máxima perda da massa (73,5\%) na temperatura de $300^{\circ} \mathrm{C}$ (Tabela 4). Nessa etapa, ocorre a emissão e combustão homogênea dos materiais voláteis, oriundos da decomposição total das hemiceluloses e celulose, além da decomposição parcial da lignina. Observa-se que a perda de massa da madeira foi acentuada em função da combustão dos voláteis provenientes da degradação térmica de estruturas de elevada massa molecular e que são os componentes químicos majoritários da madeira, as hemiceluloses e a celulose (Protásio et al., 2019). López-González et al. (2013) corroboram com esta análise e destacam que esta etapa representa a emissão de materiais voláteis e sua ignição levando à formação do carbono fixo residual que, por sua vez, irá sofrer combustão heterogênea (Figuras 2 e 3).

Tabela 4. Perda de massa e temperatura de pico, obtidas por TGA, nos estágios característicos da combustão da madeira de tachi-branco

\begin{tabular}{|c|c|c|c|c|}
\hline \multirow{2}{*}{$\begin{array}{c}\text { Espaçamento } \\
(\mathrm{m} \times \mathrm{m})\end{array}$} & \multicolumn{2}{|c|}{$1^{\circ}$ Estágio } & \multicolumn{2}{|c|}{$2^{\circ}$ Estágio } \\
\hline & $\begin{array}{c}\text { Perda de massa } \\
(\%)\end{array}$ & $\begin{array}{l}\text { Temperatura } \\
\text { máxima }\left({ }^{\circ} \mathrm{C}\right)\end{array}$ & $\begin{array}{c}\text { Perda de massa } \\
(\%)\end{array}$ & $\begin{array}{l}\text { Temperatura } \\
\text { máxima }\left({ }^{\circ} \mathrm{C}\right)\end{array}$ \\
\hline $3,0 \times 1,5$ & $73,4^{( \pm 0,8)}$ & $301,1^{( \pm 1,6)}$ & $22,5^{( \pm 1,3)}$ & $439,5^{( \pm 0,9)}$ \\
\hline $3,0 \times 2,0$ & $73,0^{( \pm 1,2)}$ & $299,4^{( \pm 0,5)}$ & $22,5^{( \pm 0,8)}$ & $441,9^{( \pm 3,8)}$ \\
\hline $3,0 \times 2,5$ & $74,0^{( \pm 1,9)}$ & $300,0^{( \pm 0,7)}$ & $21,3^{( \pm 0,4)}$ & $437,5^{( \pm 1,5)}$ \\
\hline $3,0 \times 3,0$ & $71,9^{( \pm 0,4)}$ & $300,4^{( \pm 0,2)}$ & $21,9^{( \pm 0,7)}$ & $442,9^{( \pm 3,0)}$ \\
\hline $3,0 \times 3,5$ & $73,9^{( \pm 0,8)}$ & $299,2^{( \pm 0,8)}$ & $21,3^{( \pm 0,4)}$ & $441,8^{( \pm 2,4)}$ \\
\hline $3,0 \times 4,0$ & $75,0^{( \pm 1,3)}$ & $300,1^{( \pm 0,6)}$ & $20,2^{( \pm 1,2)}$ & $443,8^{( \pm 3,6)}$ \\
\hline Média & 73,5 & 300,0 & 21,6 & 441,2 \\
\hline
\end{tabular}


A temperatura de máxima taxa de perda de massa foi de aproximadamente de $300^{\circ} \mathrm{C}$, semelhante ao observado por López-González et al. (2013) e Protásio et al. (2019) para madeira de eucalipto, cujos picos de degradação máxima ocorreram entre $290^{\circ} \mathrm{C}$ e $297,5^{\circ} \mathrm{C}$. Essa taxa máxima de perda de massa pode ser atribuída à degradação da celulose, pois é o principal constituinte químico da madeira, compondo de $40 \%$ a $45 \%$ da matéria seca da maioria das madeiras (Tenorio \& Moya, 2013; Pereira et al., 2013).

Durante o segundo estágio, que ocorreu entre as faixas de temperatura de $400^{\circ} \mathrm{C}$ a $475^{\circ} \mathrm{C}$, a máxima perda de massa foi de $21,6 \% \mathrm{com}$ pico de temperatura em $441,2^{\circ} \mathrm{C}$ (Tabela 4). Essa perda de massa está diretamente associada à combustão do carbono fixo da madeira do tachi-branco. Os teores de carbono fixo da madeira do T. vulgaris foram de $21,28 \%, 21,10 \%$, $20,95 \%, 20,59 \%, 21,01 \%$ e $20,92 \%$ para os espaçamentos de $3 \times 1,5 \mathrm{~m}, 3 \times 2,0 \mathrm{~m}, 3 \times 2,5 \mathrm{~m}, 3 \times$ 3,0 m, $3 \times 3,5$ m e $3 \times 4,0$ m, respectivamente (Silva et al., 2021).

Na segunda etapa da combustão ocorre decomposição da lignina remanescente e a combustão do carvão vegetal (carbono sólido), produzido na primeira etapa da combustão. Observa-se que a perda de massa nesse segundo estágio de decomposição foi consideravelmente inferior àquela obtida na fase inicial. Esse fato está associado à oxidação do carvão vegetal na segunda etapa, que é a fração não volátil que se oxida no estado sólido (Brand, 2010), enquanto que na primeira etapa, ocorre a queima dos voláteis que proporcionalmente representam a maior fração do combustível.

A temperatura de ignição corresponde ao ponto em que o perfil de queima aumenta intensamente (Haykiri-Açma, 2003). Em média, observa-se que a temperatura de ignição (Ti) da madeira do tachi-branco foi de $233,7^{\circ} \mathrm{C}$, próximo ao valor observado por Protásio et al. (2019), que foi de $236,1^{\circ} \mathrm{C}$ para madeira de Eucalyptus (Tabela 5). É necessário ressaltar que quanto menor for a temperatura de ignição, maior facilidade de queima do combustível (Leroy et al., 2006). A similaridade dos parâmetros da combustão da madeira de tachi-branco com a lenha proveniente de clones de Eucalyptus reforça o potencial energético da espécie estudada, pois os materiais genéticos de eucalipto são utilizados comercialmente no Brasil para a produção direta de calor e cogeração de energia.

Tabela 5. Parâmetros da combustão da madeira de tachi-branco.

\begin{tabular}{ccccc}
\hline Espaçamento $(\mathbf{m} \times \mathbf{~ m})$ & $\mathbf{T}_{\mathbf{i}}\left(^{\circ} \mathbf{C}\right)$ & $\mathbf{T}_{\mathbf{f}}\left({ }^{\circ} \mathbf{C}\right)$ & $\begin{array}{c}(\mathbf{d m} / \mathbf{d t})_{\mathbf{m a x}} \\
(\mathbf{\%} / \mathbf{m i n})\end{array}$ & $\begin{array}{c}(\mathbf{d m} \mathbf{m} \mathbf{d t})_{\text {média }} \\
\mathbf{( \% / m i n})\end{array}$ \\
\hline $3,0 \times 1,5$ & $233,3^{( \pm 1,3)}$ & $449,8^{( \pm 3,2)}$ & $8,95^{( \pm 0,4)}$ & $1,12^{( \pm 0,1)}$ \\
$3,0 \times 2,0$ & $232,2^{( \pm 3,1)}$ & $451,7^{( \pm 3,2)}$ & $8,94^{( \pm 0,4)}$ & $1,11^{( \pm 0,1)}$ \\
$3,0 \times 2,5$ & $233,9^{( \pm 1,3)}$ & $449,3^{( \pm 2,2)}$ & $9,05^{( \pm 0,3)}$ & $1,11^{( \pm 0,1)}$ \\
$3,0 \times 3,0$ & $234,3^{( \pm 1,2)}$ & $453,7^{( \pm 4,0)}$ & $8,81^{( \pm 0,2)}$ & $1,13^{( \pm 0,1)}$ \\
$3,0 \times 3,5$ & $233,7^{( \pm 0,2)}$ & $452,2^{( \pm 2,0)}$ & $8,85^{( \pm 0,4)}$ & $1,10^{( \pm 0,1)}$ \\
$3,0 \times 4,0$ & $234,9^{( \pm 1,2)}$ & $453,0^{( \pm 2,2)}$ & $9,16^{( \pm 0,1)}$ & $1,08^{( \pm 0,1)}$ \\
Média & 233,7 & 451,6 & 8,96 & 1,11 \\
\hline
\end{tabular}

$\mathrm{Ti}$ = temperatura de ignição; $\mathrm{Tf}$ = temperatura final da combustão; (dm/dt) máx = taxa máxima de perda de massa; $(\mathrm{dm} / \mathrm{dt})$ média = taxa média de perda de massa.

A temperatura final da combustão foi de $451,6^{\circ} \mathrm{C}$, sendo superior ao reportado por Protásio et al. (2019) para a madeira de clones de Eucalyptus de $439,6^{\circ} \mathrm{C}$, submetida a uma taxa de aquecimento de $5^{\circ} \mathrm{C} / \mathrm{min}$. Provavelmente, essa diferença pode ser atribuída ao maior teor de materiais voláteis da madeira de Eucalyptus reportado pelos autores (82,52\%), enquanto a madeira do tachi-branco apresentou em média 78,54\% (Silva et al., 2021). As taxas máxima e média de perda de massa foram de $8,96 \% / \mathrm{min}$ e $1,11 \% / \mathrm{min}$, respectivamente. A maior proporção de materiais voláteis em relação ao teor de carbono pode aumentar a intensidade da combustão, o consumo de massa e diminuir do tempo de queima da madeira 
(Lewandowski \& Kicherer, 1997; Protásio et al., 2019). Do mesmo modo, o acréscimo no teor de materiais voláteis na biomassa implica em uma queima mais rápida do combustível. $O$ tempo correspondente à máxima combustão (tp) foi de 54,1 min e o tempo de ignição (ti) de 40,9 min (Tabela 6).

Os índices de combustão (S) e de ignição ( $\mathrm{Di}$ ) encontrados para madeira de tachi-branco foram de 4,03 $\times 10^{7} \%^{2} /\left(\mathrm{min}^{2} / \mathrm{C}^{3}\right)$ e 4,05 $\times 10^{3} \% / \mathrm{min}^{3}$. Sahu et al. (2010) observaram índice de ignição menor de $3,54 \times 10^{3} \% / \mathrm{min}^{3}$ para o carvão de casca de arroz, ou seja, a madeira de tachi-branco estudada apresentou melhor performance na combustão comparativamente ao combustível analisado por estes autores. Já o índice característico da combustão (S) reflete a reatividade durante todo o processo de combustão, ou seja, madeira com maior valor de $S$ tem melhor desempenho de combustão (Xiong et al., 2014). Analisando os parâmetros da combustão da madeira do tachi-branco, pode-se afirmar que para produção de lenha com características de queima similares, o espaçamento de plantio não foi um fator significativo. Contudo, aspectos de crescimento e produtividade das árvores devem ser considerados na correta escolha do espaçamento de plantio para produção de madeira visando ao aquecimento e cogeração de energia na Amazônia.

Tabela 6. Parâmetros da combustão da madeira de tachi-branco (cont.).

\begin{tabular}{|c|c|c|c|c|}
\hline $\begin{array}{l}\text { Espaçamento (m } \\
\qquad \times \text { m) }\end{array}$ & tp (min) & tig (min) & $\begin{array}{c}\mathrm{S} \times 10^{7} \\
\left(\%^{2} / \min ^{2}{ }^{\circ} \mathrm{C}^{3}\right)\end{array}$ & $\operatorname{Dix} 10^{3}\left(\% \mathrm{~min}^{-3}\right)$ \\
\hline $3,0 \times 1,5$ & $54,6^{( \pm 0,8)}$ & $41,5^{( \pm 0,7)}$ & $4,1^{( \pm 0,5)}$ & $3,9^{( \pm 0,1)}$ \\
\hline $3,0 \times 2,0$ & $53,0^{( \pm 1,3)}$ & $39,8^{( \pm 1,6)}$ & $4,1^{( \pm 0,4)}$ & $4,3^{( \pm 0,4)}$ \\
\hline $3,0 \times 2,5$ & $54,3^{( \pm 0,8)}$ & $41,1^{( \pm 0,7)}$ & $4,1^{( \pm 0,2)}$ & $4,1^{( \pm 0,2)}$ \\
\hline $3,0 \times 3,0$ & $54,3^{( \pm 1,0)}$ & $40,6^{( \pm 1,5)}$ & $4,0^{( \pm 0,1)}$ & $4,0^{( \pm 0,2)}$ \\
\hline $3,0 \times 3,5$ & $54,3^{( \pm 0,5)}$ & $41,4^{( \pm 0,7)}$ & $3,9^{( \pm 0,2)}$ & $3,9^{( \pm 0,1)}$ \\
\hline $3,0 \times 4,0$ & $54,0^{( \pm 1,1)}$ & $41,1^{( \pm 1,1)}$ & $4,0^{( \pm 0,1)}$ & $4,1^{( \pm 0,2)}$ \\
\hline Média & 54,1 & 40,9 & 4,03 & 4,05 \\
\hline
\end{tabular}

tp = tempo correspondente à máxima taxa de combustão; tig = tempo de ignição; $\mathrm{S}=$ índice de combustão; $\mathrm{Di}$ = índice de ignição

\section{Efeito do espaçamento na pirólise da madeira de Tachigali vulgaris}

As Figuras 4 e 5 demonstram que as curvas TG e DTG, da madeira de tachi-branco sob atmosfera de nitrogênio, exibiram três estágios distintos de perda de massa, correspondentes à degradação térmica dos componentes químicos presentes na parede celular e a fase de secagem da amostra.

O primeiro estágio de perda de massa corresponde à perda de água na fase inicial do processo que foi de aproximadamente $8 \%$ (Tabela 7). Nessa fase, ocorre perda da água de adesão presente na parede celular e que necessita de energia para ser retirada da madeira e, portanto, trata-se de uma fase endotérmica, conforme observado no pico inverso da curva DTG (Figura 4).

$\mathrm{Na}$ faixa de temperatura compreendida entre $100^{\circ} \mathrm{C}$ e $200^{\circ} \mathrm{C}$ (Tabela 7), a perda de massa foi mínima ( $1 \%$ em média). Essa faixa de temperatura é chamada de zona de estabilidade térmica da madeira, que é limitada pela temperatura inicial de degradação térmica dos principais componentes da madeira (Pereira et al., 2013). Em estudos termogravimétricos da madeira, Santos et al. (2012) não observaram perda de massa nessa faixa de temperatura ao avaliarem quatro clones de Eucalyptus spp. aos 7 anos, corroborando com o observado para a madeira de tachi-branco. As similaridades das propriedades térmicas das madeiras de tachibranco e eucalipto evidenciam o potencial bioenergético da espécie estudada. Posteriormente, notam-se dois picos de intensa decomposição térmica, correspondendo à degradação das hemiceluloses e celulose. A faixa de decomposição térmica das hemiceluloses foi de $280^{\circ} \mathrm{C}$ a $320^{\circ} \mathrm{C}$ (Figura 4). Em média, a perda de massa foi de $17 \%$ (Tabela 6), semelhante 
ao reportado por Santos et al. (2012) que observaram perdas de massa entre 16 e 19\% para clones de Eucalyptus spp. aos 7 anos.

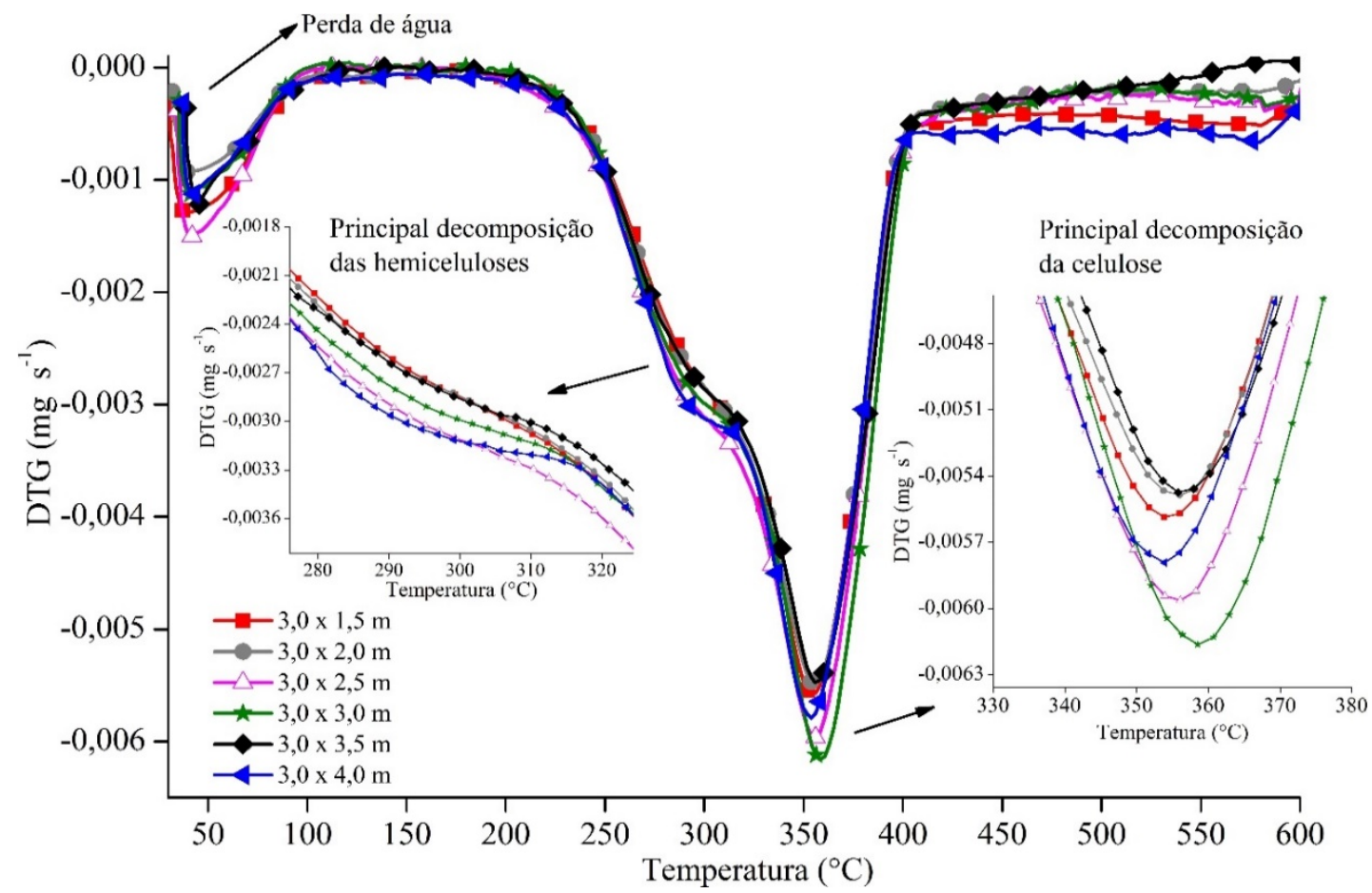

Figura 4. Curvas de DTG da madeira de tachi-branco durante a pirólise.

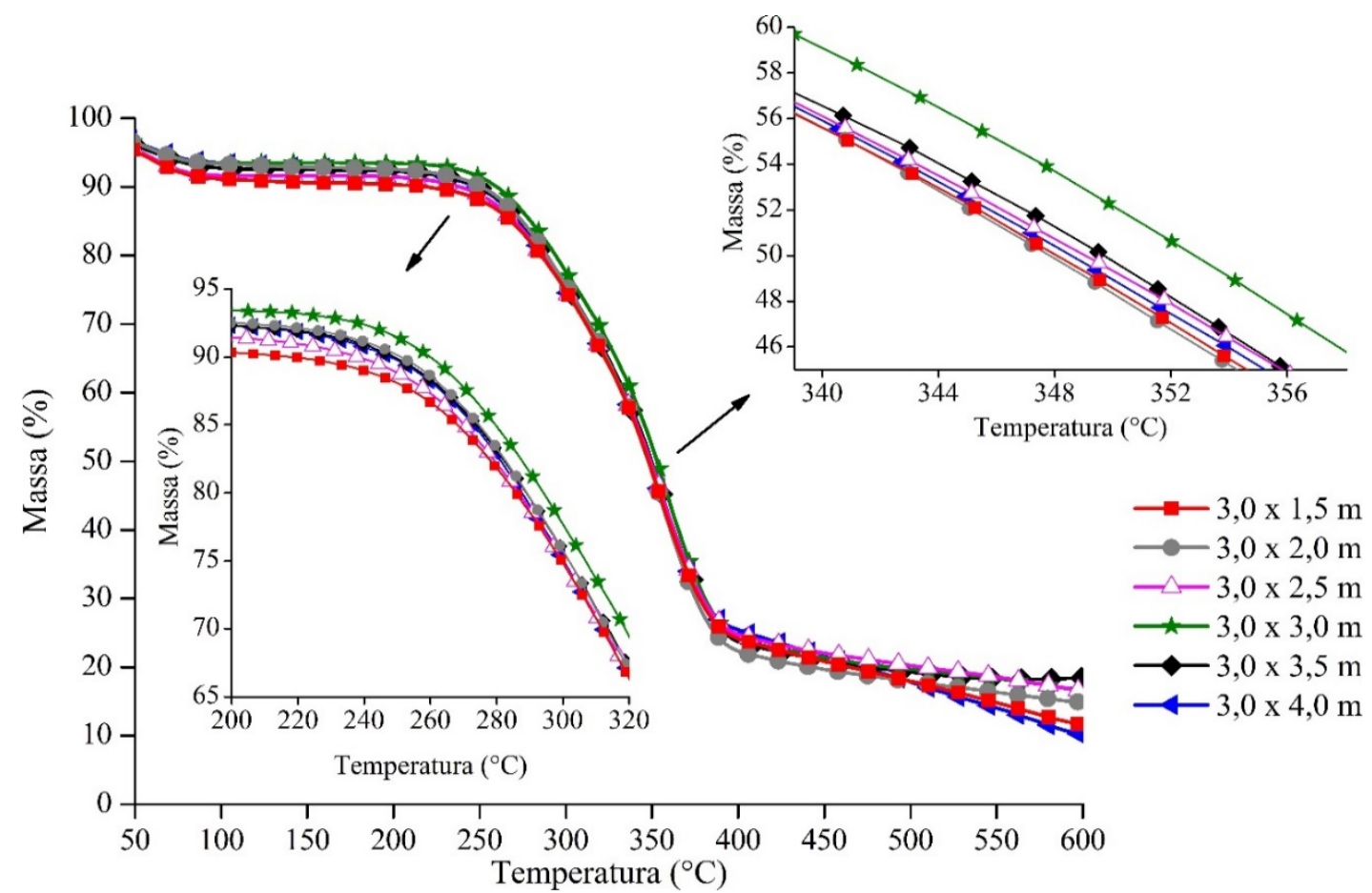

Figura 5. Curvas de TG da madeira de tachi-branco durante a pirólise.

A última fase de decomposição é caracterizada pela degradação da celulose (Yang et al., 2007). Nesta etapa, na maioria dos espaçamentos analisados, a maior perda de massa ocorreu na faixa de temperatura de $340^{\circ} \mathrm{C}$ a $380^{\circ} \mathrm{C}$ (Figura 5). Observa-se uma perda de massa de aproximadamente 50\%. Estes resultados são semelhantes aos reportados por Santos et al. 
(2012), que encontraram em média uma perda de massa de 53\% nas faixas de temperaturas entre $300^{\circ} \mathrm{C}$ e $400^{\circ} \mathrm{C}$ para clones de eucalipto. Demonstrando que a espécie tachi-branco possui propriedades térmicas análogas às espécies melhoradas geneticamente e que são comumente utilizadas para a produção de carvão vegetal no Brasil.

A partir de temperaturas próximas a $400^{\circ} \mathrm{C}$ (Figuras 4 e 5), verifica-se que a degradação térmica da madeira se tornou menor, correspondendo principalmente, à degradação de lignina. Nessa temperatura, a celulose e as hemiceluloses, componentes químicos em maior proporção na madeira, já foram degradadas, portanto a perda de massa nessa fase foi baixa, em média cerca de $5 \%$ (Pereira et al., 2013). Em temperaturas até $600^{\circ} \mathrm{C}$ as perdas de massa são maiores que $95 \%$ para hemiceluloses e maiores que $80 \%$ para a celulose, enquanto as perdas em massa de lignina não excedem 60\% (Bartkowiak \& Zakrzewski, 2004).

As massas residuais nos diferentes espaçamentos variaram de $11 \%$ a $17 \%$, em que as madeiras provenientes dos espaçamentos de 3,0 x 2,0 m, 3,0 x 2,5 m e 3,0 x 3,0 m foram as que apresentaram as maiores massas residuais (Tabela 7). Esse fato pode estar associado ao teor de lignina presente nesses espaçamentos, possibilitando uma maior resistência à degradação térmica e, consequentemente, maior massa residual. De acordo com Bartkowiak \& Zakrzewski (2004), o resíduo de carbono restante que permanece após a decomposição térmica da biomassa é derivado da lignina, em proporção superior a 50\%. Para a madeira de Eucalyptus, Rocha et al. (2016) observaram que o conteúdo de lignina pode variar conforme o espaçamento de plantio, mas os pesquisadores não constataram uma clara tendência de variação com a densidade de árvores por hectare. Os autores reportaram que o teor de lignina foi maior nas árvores plantadas em espaçamentos de 6,0 e 9,0 $\mathrm{m}^{2}$ ( 29\%) comparativamente as árvores provenientes de espaçamento reduzido de 3,0 $\mathrm{m}^{2}$ ( 26\%).

Portanto, as madeiras de tachi-branco provenientes dos espaçamentos $3,0 \times 2,0 \mathrm{~m}, 3,0 \times$ $2,5 \mathrm{~m}$ e 3,0 x 3,0 m são consideradas mais estáveis termicamente em relação às demais. Por outro lado, os espaçamentos de $3 \times 1,5 \mathrm{~m}, 3 \times 3,5 \mathrm{~m}$ e 3,0 × 4,0 m tem as menores estabilidades térmicas, pois apresentaram a menor massa residual (11\%), até a temperatura de $600^{\circ} \mathrm{C}$. É importante ressaltar que quanto mais estável termicamente a madeira, maior será o rendimento em carvão vegetal (Santos et al., 2012). Os resultados demonstram que os extremos de espaçamentos testados influenciaram o comportamento da madeira de tachibranco durante a pirólise, em que os melhores resultados foram encontrados para os espaçamentos intermediários.

Tabela 7. Parâmetros da análise térmica da pirólise da madeira de tachi-branco.

\begin{tabular}{|c|c|c|c|c|c|c|c|}
\hline \multirow{2}{*}{ Espaçamento (m x m) } & \multicolumn{6}{|c|}{ Perda de massa (\%) por faixa de temperatura $\left({ }^{\circ} \mathrm{C}\right)$} & \multirow{2}{*}{ Massa Residual (\%) } \\
\hline & $30-100$ & $100-200$ & $200-300$ & $300-400$ & $400-500$ & $500-600$ & \\
\hline $3,0 \times 1,5$ & $7^{( \pm 1,5)}$ & $1^{( \pm 0,21)}$ & $17^{( \pm 0,8)}$ & $49^{( \pm 1,5)}$ & $7^{( \pm 1,4)}$ & $7^{( \pm 2,2)}$ & 12 \\
\hline $3,0 \times 2,0$ & $7^{( \pm 0,9)}$ & $1^{( \pm 0,07)}$ & $17^{( \pm 0,5)}$ & $50^{( \pm 2,4)}$ & $5^{( \pm 0,5)}$ & $3^{( \pm 0,2)}$ & 17 \\
\hline $3,0 \times 2,5$ & $9^{( \pm 0,8)}$ & $0^{( \pm 0,06)}$ & $16^{( \pm 0,6)}$ & $50^{( \pm 0,5)}$ & $5^{( \pm 0,2)}$ & $3^{( \pm 0,2)}$ & 17 \\
\hline $3,0 \times 3,0$ & $7^{( \pm 2,8)}$ & $O^{( \pm 0,39)}$ & $16^{( \pm 0,1)}$ & $51^{( \pm 2,1)}$ & $5^{( \pm 0,6)}$ & $3^{( \pm 1,1)}$ & 17 \\
\hline $3,0 \times 3,5$ & $8^{( \pm 0,6)}$ & $1^{( \pm 0,26)}$ & $18^{( \pm 1,6)}$ & $49^{( \pm 3,6)}$ & $8^{( \pm 6,4)}$ & $5^{( \pm 5,4)}$ & 12 \\
\hline $3,0 \times 4,0$ & $8^{( \pm 1,1)}$ & $1^{( \pm 0,18)}$ & $17^{( \pm 0,5)}$ & $51^{( \pm 1,2)}$ & $7^{( \pm 1,0)}$ & $6^{( \pm 1,5)}$ & 11 \\
\hline Média & 8 & 1 & 17 & 50 & 6 & 5 & 14 \\
\hline CV (\%) & 19,3 & 56,1 & 4,8 & 4,0 & 44,0 & 56,2 & 31,7 \\
\hline
\end{tabular}

CV = coeficiente de variação.

As semelhanças na pirólise dos lenhos de T. vulgaris e Eucalyptus (Santos et al., 2012; Pereira et al., 2013) demonstram a possibilidade de uso de espécies alternativas para produção de carvão vegetal visando aos usos siderúrgicos e domésticos, principalmente na 
Amazônia. Vale ressaltar que nos estados do Pará e Maranhão, na Amazônia Legal, há demanda por carvão vegetal e biomassa para atender ao polo siderúrgico de Carajás. Contudo, os plantios florestais homogêneos são escassos nessas regiões e os resultados reportados nesta pesquisa demonstram que as características térmicas da madeira do tachibranco provenientes dos espaçamentos 3,0 × 2,0 m, 3,0 × 2,5 m e 3,0 × 3,0 m são favoráveis para a produção de biorredutor.

\section{CONCLUSÕES}

Em atmosfera de oxigênio (combustão), observaram-se duas reações principais de decomposição, em que o espaçamento de plantio não influenciou a combustibilidade da madeira de Tachigali vulgaris. A baixa temperatura de ignição $\left(233,7^{\circ} \mathrm{C}\right)$, aliada à elevada temperatura final da combustão $\left(451,6^{\circ} \mathrm{C}\right)$ e ao elevado índice de ignição $\left(4,05 \times 10^{3} \% / \mathrm{min}^{3}\right)$, demonstram que a madeira de tachi-branco apresenta características favoráveis para produção de lenha, quando comparada a outras fontes de biomassas lignocelulósicas.

Em atmosfera inerte de nitrogênio (pirólise), foram observados três estágios distintos de perda de massa, o primeiro com faixa de temperatura entre $280^{\circ} \mathrm{C}$ a $320^{\circ} \mathrm{C}$, o segundo de $340^{\circ} \mathrm{C}$ a $380^{\circ} \mathrm{C}$, e no terceiro de $400^{\circ} \mathrm{C}$ a $600^{\circ} \mathrm{C}$. Os espaçamentos de $3,0 \times 2,0 \mathrm{~m}, 3,0 \times 2,5 \mathrm{~m}$ e $3,0 \times 3,0 \mathrm{~m}$ apresentaram maiores massas residuais, o que pode indicar maior rendimento em carvão vegetal.

\section{AGRADECIMENTOS}

Ao CNPq, CAPES (código de financiamento 001) e Banco da Amazônia pelo auxílio financeiro.

Ao Grupo Jari, pela doação do material biológico utilizado e auxílio financeiro.

Aos revisores ad hoc pelas contribuições e sugestões que foram fundamentais na melhoria do artigo.

\section{REFERÊNCIAS}

Bartkowiak, M., \& Zakrzewski, R. (2004). Thermal degradation of lignins isolated from wood. Journal of Thermal Analysis and Calorimetry, 77(1), 296-304. http://dx.doi.org/10.1023/B:JTAN.0000033214.95457.fe.

Brand, M. A. (2010). Energia de biomassa florestal (131 p.). Rio de Janeiro: Interciência.

Carneiro, A. C. O., Santos, R. C., Castro, R. V. O., Castro, A. F. N. M., Pimenta, A. S., Pinto, E. M., \& Alves, I. C. N. (2013). Estudo da decomposição térmica da madeira de oito espécies da Região do Seridó, Rio Grande do Norte. Revista Árvore, 37(6), 1153-1163. http://dx.doi.org/10.1590/S010067622013000600017.

Demolinari, R., Soares, C. P. B., Leite, H. G., \& Souza, A. L. (2007). Crescimento de plantios clonais de eucalipto não desbastados na região de monte dourado (PA). Revista Árvore, 31(3), 503-512. http://dx.doi.org/10.1590/S0100-67622007000300016.

Eloy, E., Caron, B. O., Silva, D. A., Souza, V. Q., Trevisan, R., Behling, A., \& Elli, E. F. (2015). Energy productivity of forest species in short rotation plantings. Ciência Rural, 45(8), 1424-1431. http://dx.doi.org/10.1590/0103-8478cr20130177.

Eufrade-Junior, H. J., Guerra, S. P. S., Sansígolo, C. A., \& Ballarin, A. W. (2018). Management of Eucalyptus short-rotation coppice and its outcome on fuel quality. Renewable Energy, 121, 309-314. http://dx.doi.org/10.1016/j.renene.2018.01.033.

Farias, J., Marimon, B. S., Silva, L. C. R., Petter, F. A., Andrade, F. R., Morandi, P. S., \& Marimon-Junior, B. $\mathrm{H}$. (2016). Survival and growth of native Tachigali vulgaris and exotic Eucalyptus urophylla $x$ Eucalyptus grandis trees in degraded soils with biochar amendment in southern Amazonia. Forest Ecology and Management, 368, 173-182. http://dx.doi.org/10.1016/j.foreco.2016.03.022.

García, R., Pizarro, C., Lavín, A. G., \& Bueno, J. L. (2012). Characterization of Spanish biomass wastes for energy use. Bioresource Technology, 103(1), 249-258. PMid:22050839. http://dx.doi.org/10.1016/j.biortech.2011.10.004. 
Haykiri-Açma, H. (2003). Combustion characteristics of different biomass materials. Energy Conversion and Management, 44(1), 155-162. http://dx.doi.org/10.1016/S0196-8904(01)00200-X.

Leroy, V., Cancellieri, D., \& Leoni, E. (2006). Thermal degradation of ligno-cellulosic fuels: DSC and TGA studies. Thermochimica Acta, 451(1/2), 131-138. http://dx.doi.org/10.1016/j.tca.2006.09.017.

Lewandowski, I., \& Kicherer, A. (1997). Combustion quality of biomass: practical relevance and experiments to modify the biomass quality of Miscanthus x giganteus. European Journal of Agronomy, 6(3/4), 163-177. http://dx.doi.org/10.1016/S1161-0301(96)02044-8.

Li, L., Zhao, N., Fu, X., Shao, M., \& Qin, S. (2013). Thermogravimetric and kinetic analysis of Spirulina wastes under nitrogen and air atmospheres. Bioresource Technology, 140(1), 152-157. PMid:23693145. http://dx.doi.org/10.1016/j.biortech.2013.04.121.

López-González, D., Fernandez-Lopez, M., Valverde, J. L., \& Sanchez-Silva, L. (2013). Thermogravimetricmass spectrometric analysis on combustion of lignocellulosic biomass. Bioresource Technology, 143(1), 562-574. PMid:23835261. http://dx.doi.org/10.1016/j.biortech.2013.06.052.

Moon, C., Sung, Y., Ahn, S., Kim, T., Choi, G., \& Kim, D. (2013). Effect of blending ratio on combustion performance in blends of biomass and coals of different ranks. Experimental Thermal and Fluid Science, 47(1), 232-240. http://dx.doi.org/10.1016/j.expthermflusci.2013.01.019.

Moulin, J. C., Arantes, M. D. C., Vidaurre, G. B., Paes, J. B., \& Carneiro, A. C. O. (2015). Efeito do espaçamento, da idade e da irrigação nos componentes químicos da madeira de eucalipto. Revista Árvore, 39(1), 199-208. http://dx.doi.org/10.1590/0100-67622015000100019.

Orellana, B. B. M. A., Vale, A. T., Gonçalez, J., Guedes, M. C., Orellana, J. B. P., \& Lima, C. M. (2018). Produtividade energética da madeira de Tachigali vulgaris por classe diamétrica em plantios experimentais na Amazônia. Nativa, 6, 773-781. http://dx.doi.org/10.31413/nativa.v6i0.5130.

Pereira, B. L. C., Carneiro, A. C. O., Carvalho, A. M. M. L., Trugilho, P. F., Melo, I. C. N. A., \& Oliveira, A. C. (2013). Estudo da degradação térmica da madeira de Eucalyptus através de termogravimetria e calorimetria. Revista Árvore, 37(3), 567-576. http://dx.doi.org/10.1590/S0100-67622013000300020.

Protásio, T. P., Guimarães Junior, M., Mirmehdi, S., Trugilho, P. F., Napoli, A., \& Knovack, K. M. (2017). Combustion of biomass and charcoal made from babassu nutshell. Cerne, 23(1), 1-10. http://dx.doi.org/10.1590/01047760201723012202.

Protásio, T. P., Scatolino, M. V., Araújo, A. C. C., \& Oliveira, A. F. (2019). Assessing proximate composition, extractive concentration, and lignin quality to determine appropriate parameters for selection of superior Eucalyptus firewood. BioEnergy Research, 12(3), 626-641. http://dx.doi.org/10.1007/s12155019-10004-x.

Qian, W., Xie, Q., Huang, Y., Dang, J., Sun, K., Yang, Q., \& Wang, J. (2012). Combustion characteristics of semicokes derived from pyrolysis of low rank bituminous coal. International Journal of Mining Science and Technology, 22(5), 645-650. http://dx.doi.org/10.1016/j.jimst.2012.08.009.

Ragland, K. W., Aerts, D. J., \& Baker, A. J. (1991). Properties of wood for combustion analysis. Bioresource Technology, 37(2), 161-168. http://dx.doi.org/10.1016/0960-8524(91)90205-X.

Rocha, M. F. V., Vital, B. R., Carneiro, A. C. O., Carvalho, A. M. M. L., Cardoso, M. T., \& Hein, P. R. G. (2016). Effect of plant spacing on the physical, chemical and energy properties of Eucalyptus wood and bark. Journal of Tropical Forest Science, 28, 243-248.

Rolim, S. G., \& Piotto, D. (2018). Silvicultura e tecnologia de espécies da Mata Atlântica (160p.). Belo Horizonte: Editora Rona.

Sahu, S. G., Sarkar, P., Chakraborty, N., \& Adak, A. K. (2010). Thermogravimetric assessment of combustion characteristics of blends of a coal with different biomass chars. Fuel Processing Technology, 91(3), 369-378. http://dx.doi.org/10.1016/j.fuproc.2009.12.001.

Santos, R. C., Carneiro, A. C. O., Trugilho, P. F., Mendes, L. M., \& Carvalho, A. M. M. L. (2012). Análise termogravimétrica em clones de eucalipto como subsídio para a produção de carvão vegetal. Cerne, 18(1), 143-151. http://dx.doi.org/10.1590/S0104-77602012000100017.

Silva, M. O. S., Silva, M. G., Bufalino, L., Assis, M. R., Gonçalves, D. A., Trugilho, P. F., \& Protásio, T. P. (2021). Variations in productivity and wood properties of Amazonian tachi-branco trees planted at different spacings for bioenergy purposes. Journal of Forestry Research, 32(1), 211-224. http://dx.doi.org/10.1007/s11676-019-01068-8.

Souza, C. R., Lima, R. M. B., Azevedo, C. P., \& Rossi, M. B. (2008). Desempenho de espécies florestais para uso múltiplo na Amazônia. Scientia Forestalis, 36(77), 7-14. 
Tenorio, C., \& Moya, R. (2013). Thermogravimetric characteristics, its relation with extractives and chemical properties and combustion characteristics of ten fast-growth species in Costa Rica. Thermochimica Acta, 563(1), 12-21. http://dx.doi.org/10.1016/j.tca.2013.04.005.

Tomaselli, I., Marques, L. C. T., Carpanezzi, A. A., \& Pereira, J. C. D. (1983). Caracterização da madeira de tachi-branco-da-terra-firme (Sclerolobiurn paniculatum Vogel) para energia. Boletim de Pesquisa Florestal, (6), 33-44.

Tonini, H., Schwengber, D. R., Morales, M. M., \& Oliveira, J. M. F. (2018). Crescimento e qualidade energética da madeira de Tachigali vulgaris sob diferentes espaçamentos. Pesquisa Florestal Brasileira, 38, e201801569. http://dx.doi.org/10.4336/2018.pfb.38e201801569.

Xiong, S., Zhang, S., Wu, Q., Guo, X., Dong, A., \& Chen, C. (2014). Investigation on cotton stalk and bamboo sawdust carbonization for barbecue charcoal preparation. Bioresource Technology, 152(1), 86-92. PMid:24280085. http://dx.doi.org/10.1016/j.biortech.2013.11.005.

Yang, H., Yan, R., Chen, H., Lee, D. H., \& Zheng, C. (2007). Characteristics of hemicellulose, cellulose and lignin pyrolysis. Fuel, 86(12-13), 1781-1788. http://dx.doi.org/10.1016/j.fuel.2006.12.013.

Contribuição dos Autores: MOSS: Conceituação, Curadoria dos Dados, Análise Formal, Metodologia Visualização, Escrita - Primeira Redação, Escrita - Revisão e Edição; MGS: Conceituação, Metodologia, Administração do Projeto, Supervisão; LB: Escrita - Primeira Redação, Escrita - Revisão e Edição; MRA: Investigação, Metodologia; DAG: Obtenção de Financiamento, Recursos, Administração de Projetos, Supervisão, Escrita - Revisão e Edição; PFT: Obtenção de Financiamento, Recursos, Administração de Projetos, Supervisão, Escrita - Revisão e Edição; TPP: Conceituação, Análise Formal, Obtenção de Recurso, Metodologia, Administração do Projeto, Supervisão, Visualização, Escrita - Primeira Redação, Escrita - Revisão e Edição. 